\title{
The durability and effectiveness of sensor-augmented insulin pump therapy in pediatric and young adult patients with type 1 diabetes
}

Yun Jeong Lee, MD', Young Ah Lee, MD, PhD', Jae Hyun Kim, MD, PhD', Hye Rim Chung, MD, PhD², Min Jeong $\mathrm{Gu}^{3}$, Ji Young $\mathrm{Kim}^{4}$, Choong Ho Shin, MD, PhD

'Department of Pediatrics, Seoul National University Children's Hospital, Seoul, Korea

${ }^{2}$ Department of Pediatrics, Seoul National University Bundang Hospital, Seongnam, Korea

${ }^{3}$ Pediatric Diabetes Education Unit, Seoul National University Children's Hospital, Seoul, Korea

${ }^{4}$ Department of Food Nutrition Service and Nutrition Care, Seoul National University Children's Hospital, Seoul, Korea

Received: 24 March, 2020

Revised: 12 May, 2020

Accepted: 19 May, 2020

Address for correspondence:

Choong Ho Shin, MD, PhD

Department of Pediatrics, Seoul National University Children's Hospital, 101 Daehak-ro, Jongno-gu, Seoul 03080, Korea

Tel: $+82-2-2072-3357$

Fax: +82-743-3455

E-mail: chshinpd@snu.ac.kr

https://orcid.org/0000-0002-98131134
Purpose: Despite the prevalent use of insulin pump therapy worldwide, few studies have been conducted among young patients with type 1 diabetes (T1D) in Korea. We investigated the durability and effectiveness of insulin pump therapy among Korean pediatric and young adult patients with T1D.

Methods: This study included 54 patients with T1D diagnosed at pediatric ages (range, 1.1-14.1 years) who initiated insulin pump therapy during 2016-2019 at Seoul National University Children's Hospital and Seoul National University Bundang Hospital. Clinical and biochemical data, including anthropometric measurements, insulin dose, and glycated hemoglobin ( $\mathrm{HbA1c}$ ) levels were obtained from T1D diagnosis to last follow-up.

Results: Forty-four patients (81.5\%) continued insulin pump therapy with a median pump use duration of 2.9 years (range, $0.2-3.5$ years); 10 discontinued the therapy within 12 months ( $<1$ month, $\mathrm{n}=6$; $1-6$ months, $\mathrm{n}=1$; and $6-12$ months, $\mathrm{n}=3$ ) due to physical interferences or financial problems. Older age ( $\geq 10$ years of age) and longer diabetes duration ( $\geq 2$ years) at the initiation of pump therapy were associated with discontinuation ( $P<0.05$ for both). For patients continuing pump therapy, $\mathrm{HbA} 1 \mathrm{c}$ levels significantly decreased after 1 year of therapy (from $8.9 \%$ to $8.1 \%, P<0.001$ ) without changes in the body mass index $z$-scores or insulin dose. Although 4 patients experienced diabetic ketoacidosis, all recovered without complications.

Conclusion: Insulin pump therapy was effective in improving glycemic control in T1D patients during 12 months of treatment. Early initiation of insulin pump therapy after T1D diagnosis was helpful for continuing therapy.

Keywords: Insulin infusion system, Type 1 diabetes mellitus, Treatment outcome, Glycated hemoglobin A

\section{Introduction}

Type 1 diabetes (T1D) is a chronic disease caused by the autoimmune destruction of pancreatic beta cells and insulin deficiency. The treatment goal for T1D is to maintain target glucose levels to prevent microvascular and cardiovascular complications. ${ }^{1)}$ In addition to achieving the target glycated hemoglobin ( $\mathrm{HbAlc}$ ) levels, the important targets of minimizing glycemic variability and preventing hypoglycemia have been emphasized as the ultimate treatment goals for T1D patients. ${ }^{2)}$

Regarding these goals, T1D management has been significantly improved with the progress of continuous glucose monitoring (CGM) systems and insulin pumps. ${ }^{3)}$ Since the first insulin pump was introduced in the early 1980s, insulin pump therapy has become a well-established, safe, and effective treatment for T1D adult and pediatric patients. ${ }^{4}$ In recent years, the sensoraugmented pump (SAP), which combines the technology of an insulin pump and a CGM, can 
provide a threshold-suspend function to prevent hypoglycemia. With the advent of diabetes technologies, optimal glycemic control can be achieved among pediatric patients without increasing the risk of hypoglycemia. ${ }^{5)}$ Consequently, the International Society of Pediatric and Adolescent Diabetes ${ }^{6)}$ and the American Diabetes Association ${ }^{7)}$ lowered the HbAlc glycemic target for children and adolescents from $7.5 \%$ to $7.0 \%$.

While the use of insulin pumps has expanded, there is still variability depending on the region, ${ }^{8)}$ ethnic group, and socioeconomic status (SES) of the patient. ${ }^{9)}$ Although the incidence of T1D in Korea is low, a recent study has reported an increasing trend ${ }^{10)}$ similar to that observed in other countries. ${ }^{11)}$ The use of SAPs was approved in Korea in 2016; ${ }^{12)}$ however, they have not been widely used in routine practice due to their high cost. Since the National Health Insurance Service has been providing partial reimbursements for insulin pump devices since $2020,{ }^{13)}$ more prevalent use of insulin pump therapy is expected. Due to a limited number of insulin pump users to date, no studies have investigated the efficacy of insulin pump therapy in this patient population. In this study, we evaluated the durability and effectiveness of insulin pump therapy among Korean pediatric and young adult patients with T1D.

\section{Materials and methods}

\section{Participants}

This retrospective study included 54 patients with T1D diagnosed at pediatric ages (range, 1.1-14.1 years), who initiated insulin pump therapy with SAPs between August 2016 and November 2019 at the Seoul National University Children's Hospital $(\mathrm{n}=47)$ and Seoul National University Bundang Hospital ( $n=7)$. In May 2016, the use of SAP devices (Minimed 640G; Medtronic, Northridge, CA, USA) was approved by the Korean Ministry of Food and Drug Safety, ${ }^{12)}$ and all of the patients who initiated SAP therapy after official approval were included in this study.

\section{Clinical and biochemical data}

Data on demographic characteristics, anthropometric measurements, SES, and factors affecting diabetes management from T1D diagnosis to last follow-up were obtained from medical records. Height $(\mathrm{cm})$ was measured using a Harpenden stadiometer (Holtain Ltd., Crymych, Wales, UK), and weight was measured using a digital scale (150 A; Cas Co., Ltd., Seoul, Korea). Body mass index (BMI) was calculated as weight divided by height in meters squared $\left(\mathrm{kg} / \mathrm{m}^{2}\right)$. The height, weight, and BMI $z$-scores were determined on the basis of the 2017 Korean National Growth Charts. ${ }^{14)}$ Pubertal status was assessed using the Tanner staging for breasts (females) and genitals (males). The HbAlc level was determined using immunoturbidimetry at Seoul National University Children's Hospital and high-performance liquid chromatography at Seoul
National University Bundang Hospital. Diabetic ketoacidosis (DKA) was defined as hyperglycemia with venous blood $\mathrm{pH}$ $<7.3$ or bicarbonate level $<15 \mathrm{mmol} / \mathrm{L}$. DKA severity was categorized according to the degree of acidosis, as follows: mild ( $\mathrm{pH}<7.3$ or bicarbonate level $<15 \mathrm{mmol} / \mathrm{L}$ ), moderate $(\mathrm{pH}$ $<7.2$ or bicarbonate level $<10 \mathrm{mmol} / \mathrm{L}$ ), and severe $(\mathrm{pH}<7.1$ or bicarbonate level $<5 \mathrm{mmol} / \mathrm{L}){ }^{15)}$ The SES was determined according to the type of health insurance stratified as National Health Insurance and Medical Aid beneficiaries. ${ }^{16)}$

\section{Initiation protocol for insulin pump therapy}

The decision to initiate insulin pump therapy was made based on clinical grounds and the preferences of the patients and their families. The majority of patients $(n=47)$ initiated insulin pump therapy through a 4-day inpatient program, which consisted of the implantation of the device, monitoring of glucose levels, and educational training. The remaining patients $(n=7)$ started insulin pump therapy through an outpatient educational program. Both programs offered structured education by diabetes specialist nurses and dietitians, who demonstrated the basic principles of insulin pump therapy and the CGM system, initial pump settings (basal rate, insulin-to-carbohydrate ratio, and insulin sensitivity factor), basal rate adjustment, insulin bolus options, interpretation and calibration of the CGM, infusion set management, and the potential complications of pump or infusion set failure (mainly DKA). All patients were instructed to change the infusion set every 3 days. Because Medtronic Korea offered a 1-month free trial of the MiniMed $640 \mathrm{G}$ to T1D patients, they were able to decide whether to purchase the device and continue with the therapy after the trial. Patients who decided not to use the insulin pump returned to their previous insulin therapies.

\section{Statistical analysis}

Statistical analyses were performed using the IBM SPSS Statistics ver. 25.0, (IBM Corp., Armonk, NY, USA). All continuous variables are presented as median values with interquartile ranges, and the Mann-Whitney $U$-test was used to compare continuous variables between the 2 groups. The chisquare test or Fisher exact test was used to compare categorical variables between the 2 groups. The Wilcoxon signed-rank test was used to compare BMI $z$-scores, HbAlc levels, and total daily doses of insulin (TDDs) before and 1 year after initiation of pump therapy within groups. $P$-values less than 0.05 were considered statistically significant.

\section{Results}

\section{Baseline characteristics of the participants}

Table 1 shows the baseline characteristics of the 54 patients $(25$ boys and 29 girls). The median age at diabetes diagnosis was 7.4 
years (range, 1.1-14.1 years). Prior to pump therapy, 8 patients (14.8\%) were being treated with twice-daily injections and 42 patients $(77.8 \%)$ with multiple daily injections (MDI). Four patients $(7.4 \%)$ started insulin pump therapy from diagnosis. Ten patients (18.5\%) had used a CGM device before insulin pump therapy. Two patients (3.7\%) experienced DKA within a year prior to the initiation of pump therapy. At the time of pump therapy initiation, the median age of the participants was 12.0 years (range, 2-26.4 years), 18 participants (33.3\%) were prepubertal, and the median duration of diabetes was 3.7 years (range, 0-19.3 years). The baseline median BMI $z$-score was 0.3, and the median $\mathrm{HbAlc}$ level was $8.7 \%$, with a median TDD of $0.8 \mathrm{U} / \mathrm{kg} /$ day. Six patients $(11.1 \%$ ) had comorbidities such as hyperthyroidism, hypothyroidism, myasthenia gravis, juvenile idiopathic arthritis, and transverse myelitis. Eleven patients (20.4\%) were categorized as Medical Aid beneficiaries according to their health insurance status.

\section{Adherence to insulin pump therapy}

Among the 54 patients, 44 (81.5\%) continued insulin pump therapy throughout the study, with a median duration of insulin pump use of 2.9 years (range, $0.2-3.5$ years). Among them,
2 patients switched from SAP to conventional insulin pump therapy (Dana Diabecare R, Sooil) after the 1-month trial. Forty-one (93.2\%) used insulin pumps provided with real-time CGM; 3 patients refused to use the CGM due to skin reactions $(n=2)$ or financial constraints $(n=1)$. The other 10 patients (18.5\%) discontinued the insulin pump therapy and decided to return to MDI therapy, with a median time of pump use of 0.1 years (range, $0.0-1.0$ years).

No differences were observed between the 2 groups in terms of sex ratio, mean age at diagnosis, prior insulin regimen, CGM device use, or episodes of DKA prior to pump therapy initiation (Table 1). However, during the initiation of insulin pump therapy, the discontinuation group had a higher proportion of older patients ( $\geq 10$ years of age; $100 \%$ vs. $63.6 \%, P=0.024$ ) and patients with longer diabetes duration ( $\geq 2$ years; $100 \%$ vs. $54.5 \%, P=0.020)$ than the continuation group. No differences were found in pubertal statuses, BMI $z$-scores, or HbAlc levels between the 2 groups. The discontinuation group had a higher median TDD at the start of insulin pump therapy than the continuation group ( 0.9 vs. $0.8 \mathrm{IU} / \mathrm{kg} /$ day, $P=0.034$ ). However, the result was not significant after adjusting for diabetes duration $(P=0.095$, data not shown). Education type (inpatient or outpatient based), SES (as assessed according to health

Table 1. Clinical characteristics of the patients at pump therapy initiation

\begin{tabular}{|c|c|c|c|c|}
\hline Characteristic & $\begin{array}{l}\text { Overall } \\
(n=54)\end{array}$ & $\begin{array}{l}\text { Continued pump therapy } \\
\qquad(n=44)\end{array}$ & $\begin{array}{l}\text { Discontinued pump therapy } \\
\qquad(n=10)\end{array}$ & $P$-value \\
\hline Male sex & $25(46.3)$ & $19(43.2)$ & $6(60.0)$ & 0.541 \\
\hline Age at diagnosis (yr) & $7.4(3.7-10.1)$ & $6.9(4.7-8.4)$ & $7.7(3.6-10.5)$ & 0.511 \\
\hline Insulin regimen prior to pump therapy & & & & 0.173 \\
\hline Twice-daily injection & $8(14.8)$ & $8(18.2)$ & $0(0)$ & \\
\hline Multiple daily injection & $42(77.8)$ & $32(72.7)$ & $10(100)$ & \\
\hline Use of insulin pump from the diagnosis & $4(7.4)$ & $4(9.1)$ & $0(0)$ & \\
\hline Use of CGM device prior to pump therapy & $10(18.5)$ & $9(20.1)$ & $1(10.0)$ & 0.751 \\
\hline Occurrence of DKA in a year prior to pump therapy initiation & $2(3.7)$ & $2(4.5)$ & $0(0)$ & 1.000 \\
\hline Age at pump therapy initiation (yr) & $12.0(8.6-14.8)$ & $12.6(12.0-14.8)$ & $13.8(6.9-14.7)$ & 0.166 \\
\hline$<10$ years old & $16(29.6)$ & $16(36.4)$ & $0(0)$ & 0.024 \\
\hline$\geq 10$ years old & $38(70.4)$ & $28(63.6)$ & $10(100)$ & \\
\hline Duration of diabetes at pump therapy initiation (yr) & $3.7(1.5-6.6)$ & $2.6(1.0-6.2)$ & $6.8(4.9-9.9)$ & 0.009 \\
\hline$<2$ years & $20(37.0)$ & $20(45.5)$ & $0(0)$ & 0.020 \\
\hline$\geq 2$ years & $34(63.0)$ & $24(54.5)$ & $10(100)$ & \\
\hline Pubertal status at pump therapy initiation & & & & 0.601 \\
\hline Prepubertal & $18(33.3)$ & $16(36.4)$ & $2(20.2)$ & \\
\hline Tanner 2-4 & $17(31.5)$ & $13(29.5)$ & $4(40.0)$ & \\
\hline Tanner 5 & $19(35.2)$ & $15(34.1)$ & $4(40.0)$ & \\
\hline Body mass index $z$-score at pump therapy initiation & $0.26(-0.73$ to 0.92$)$ & $0.24(-0.74$ to 0.87$)$ & $0.29(-0.25$ to 0.94$)$ & 0.556 \\
\hline $\mathrm{HbA1c}(\%)$ at pump therapy initiation & $8.7(7.6-9.7)$ & $8.7(7.6-9.6)$ & $8.8(8.0-9.7)$ & 0.785 \\
\hline Total daily insulin dose (U/kg/day) at pump therapy initiation & $0.78(0.64-1.01)$ & $0.77(0.62-1.00)$ & $0.94(0.79-1.21)$ & 0.034 \\
\hline Inpatient education for insulin pump & $47(87.0)$ & $39(88.6)$ & $8(80.0)$ & 0.385 \\
\hline Coexisting disease & $6(11.1)$ & $5(11.4)$ & $1(10.0)$ & 0.985 \\
\hline Health insurance type & & & & 0.687 \\
\hline National Health Insurance & $43(79.6)$ & $36(81.8)$ & $7(70.0)$ & \\
\hline Medical Aid & $11(20.4)$ & $8(18.2)$ & $3(30.0)$ & \\
\hline
\end{tabular}

Values are presented as number (\%) or median (interquartile range).

DKA, diabetic ketoacidosis; CGM, continuous glucose monitoring; HbA1c, glycated hemoglobin. 
insurance type), and presence of comorbidities did not differ significantly.

\section{Timing and causes of insulin pump therapy discontinuation}

Ten patients discontinued the insulin pump therapy within 12 months ( $<1$ month, $\mathrm{n}=6$; $1-6$ months, $\mathrm{n}=1$; and $6-12$ months, $\mathrm{n}=3$ ) (Table 2). The most common cause of discontinuation was physical problems $(n=5)$, including skin reactions at the insertion site or interference with sports and other activities $(n=2)$. Three patients discontinued the treatment due to financial constraints, and others claimed that they disliked the pump. During the follow-up, 3 patients restarted insulin pump therapy. Among them, 2 patients had discontinued the treatment due to financial constraints but had restarted the therapy with support from the hospital's financial assistance program, while one patient had discontinued the treatment due to dislike of pump use but restarted the therapy because of poor glycemic control with MDI and assurance from the clinician and parents.

\section{Metabolic outcomes of insulin pump therapy after 1 year}

We compared the BMI $z$-scores, HbAlc levels, and TDDs at

$\begin{aligned} & \text { Table 2. Timing and reasons for discontinuation of insulin pump } \\
& \text { therapy }\end{aligned}$
\begin{tabular}{lc}
\hline Variable & No. of patients (\%) \\
\hline Timing of discontinuation & $6(60.0)$ \\
Before 1 month (nonpurchase) & $1(10.0)$ \\
Between 1 and 6 months & $3(30.0)$ \\
Between 6 and 12 months & \\
Reasons for discontinuation & $5(50.0)$ \\
Physical problem & 3 \\
Skin reactions at the insertion site and/or & \\
$\quad$ due to adhesive & 2 \\
Interference with sports and physical activities & $3(30.0)$ \\
Financial constraints & $2(20.0)$ \\
Dislike of the pump & \\
\hline
\end{tabular}

the time of initiation of pump therapy and 1 year after initiation of insulin pump therapy within groups and between groups. Of the patients from the continuation group using an insulin pump for at least 1 year $(n=38), 7$ were excluded as they had initiated insulin pump therapy within a year of their diabetes diagnosis, considering the effects of the "honeymoon phase" and rapid metabolic changes. A total of 31 patients from the continuation group were included in the analyses.

After 1 year of insulin pump therapy, the HbAlc level improved in 25 patients (80.6\%), and the median HbAlc level decreased significantly from $8.9 \%$ to $8.1 \%(P<0.001)$ (Table 3 , Supplementary Fig. 1). Compared to the baseline values, no significant changes were found in terms of BMI $z$-scores and TDDs during pump therapy. Subgroup analyses showed consistent results for patients treated with MDI prior to pump therapy $(\mathrm{n}=27)$, with the median HbAlc level decreasing from $9.0 \%$ to $8.2 \%(P=0.001)$ without significant increase in BMI $z$-scores and TDDs (all $P>0.05$, data not shown). For the 7 patients who initiated insulin pump therapy within 1 year after their diagnosis of diabetes, median BMI $z$-scores changed from -0.18 to 0.76 , HbAlc from $9.1 \%$ to $7.3 \%$, and TDD from 0.56 to $0.88 \mathrm{U} / \mathrm{kg} /$ day without statistical significance (all $P>0.05$ ). The discontinuation group showed no significant changes in BMI $z$-score, HbAlc, and TDD from the baseline to 1 year after insulin pump therapy (all $P>0.05$ ). The HbAlc change from baseline to 1 year after pump therapy differed significantly between the continuation and discontinuation groups (-0.7 vs. $0.2, P=0.014$ ) (Table 3).

\section{DKA during insulin pump therapy}

Four episodes of DKA occurred in 4 patients during insulin pump therapy in this cohort (Table 4). All cases involved girls, and the duration of insulin pump therapy at the time of DKA episodes ranged from 0.7 to 1.4 years. Two patients experienced infusion set failures (inappropriate changes of infusion sets), and the other 2 missed boluses for a few days before the development of DKA. No cases of DKA caused by pump device failure were observed in this study, and all patients recovered

Table 3. Metabolic outcomes after 1 year of insulin pump therapy initiation

\begin{tabular}{|c|c|c|c|c|c|c|c|}
\hline \multirow[b]{2}{*}{$\begin{array}{l}\text { Metabolic } \\
\text { outcomes }\end{array}$} & \multicolumn{3}{|c|}{ Continued pump therapy over 1 year group $(n=31)^{*}$} & \multicolumn{3}{|c|}{ Discontinued pump therapy group $(n=10)$} & \multirow{2}{*}{$\begin{array}{c}P \text {-value for change } \\
\text { from baseline } \\
\text { between groups }\end{array}$} \\
\hline & $\begin{array}{l}\text { At the initiation of } \\
\text { pump therapy }\end{array}$ & $\begin{array}{l}1 \text { Year after pump } \\
\text { therapy initiation }\end{array}$ & $P$-value ${ }^{\dagger}$ & $\begin{array}{l}\text { At the initiation of } \\
\text { pump therapy }\end{array}$ & $\begin{array}{l}1 \text { Year after pump } \\
\text { therapy initiation }\end{array}$ & $P$-value ${ }^{\dagger}$ & \\
\hline BMI z-score & $\begin{array}{c}0.33 \\
(-0.62 \text { to } 0.81)\end{array}$ & $\begin{array}{c}0.16 \\
(-0.31 \text { to } 1.24)\end{array}$ & 0.315 & $\begin{array}{c}0.29 \\
(-0.25 \text { to } 0.94)\end{array}$ & $\begin{array}{c}0.83 \\
(-0.29 \text { to } 1.08)\end{array}$ & 0.646 & 0.962 \\
\hline HbA1c (\%) & $\begin{array}{c}8.9 \\
(8.0-10.1)\end{array}$ & $\begin{array}{c}8.1 \\
(7.4-9.2)\end{array}$ & $<0.001$ & $\begin{array}{c}8.8 \\
(8.0-9.7)\end{array}$ & $\begin{array}{c}9.0 \\
(8.3-9.9)\end{array}$ & 0.610 & 0.014 \\
\hline TDD (U/kg/day) & $\begin{array}{c}0.81 \\
(0.69-1.03)\end{array}$ & $\begin{array}{c}1.00 \\
(0.81-1.14)\end{array}$ & 0.057 & $\begin{array}{c}0.94 \\
(0.79-1.21)\end{array}$ & $\begin{array}{c}1.24 \\
(1.11-1.29)\end{array}$ & 0.068 & 0.347 \\
\hline
\end{tabular}

Values are presented as median (interquartile range).

BMI, body mass index; HbA1c, glycated hemoglobin; TDD, total daily dose of insulin.

*Among 38 patients who continued pump therapy over 1 year, 7 patients with diabetes duration $<1$ year at the time of insulin pump initiation were excluded. ${ }^{\dagger} P$-values were derived from Wilcoxon signed rank test (within group comparison). ${ }^{\ddagger} P$-values were derived from Mann-Whitney U-test (between group comparison). 
Table 4. Patients who developed diabetic ketoacidosis during insulin pump therapy

\begin{tabular}{lcccccc}
\multirow{2}{*}{ No. } & Sex & \multicolumn{5}{c}{ At the time of diabetic ketoacidosis (DKA) episode } \\
\cline { 3 - 7 } & & Age (yr) & Diabetes duration (yr) & Duration of insulin pump therapy (yr) & Degree of DKA & Reasons for DKA \\
\hline 1 & $F$ & 9.9 & 2.6 & 0.7 & Severe & Infusion set failure+gastroenteritis \\
2 & $F$ & 12.8 & 11.6 & 1.4 & N/A & Missing bolus \\
3 & $F$ & 16.0 & 2.5 & 0.6 & Severe & Infusion set failure+alcohol consumption \\
4 & $F$ & 20.1 & 10.5 & 1.0 &
\end{tabular}

without complications.

\section{Discussion}

To the best of our knowledge, this is the first study reporting the clinical outcomes of insulin pump therapy among pediatric and young adult patients with T1D in Korea. In this study, $81.5 \%$ of the patients continually received pump therapy, with a median duration of pump use of 2.9 years. Those who discontinued pump therapy were older and had a longer duration of diabetes at the initiation of pump therapy. Most patients discontinued treatment within a year due to physical discomfort or financial problems. Improved glycemic control without a significant increase in BMI $z$-scores and TDD was found among patients who were receiving ongoing insulin pump therapy.

Although more than $80 \%$ of our patients continually received pump therapy, the discontinuation rate in this study was higher $(18.5 \%)$ than that observed in previous studies. ${ }^{17-21)}$ In general, discontinuation of insulin pump therapy among pediatric T1D patients is not common, ${ }^{4)}$ and data from the German/Austrian Diabetes Patienten Verlausdokumentation registry $^{17)}$ and the US-based T1D Exchange Clinic registry ${ }^{19)}$ have shown overall discontinuation rates of $3 \%$ to $4 \%$. A singlecenter study from Israel reported that $11.3 \%$ of pediatric patients with T1D discontinued pump therapy during a 9-year follow-up. ${ }^{18)}$ The differences in insurance coverage for insulin pumps and supplies among countries, as well as cultural differences, including perceptions of insulin pump devices, may affect the discontinuation rates. ${ }^{8,22)}$ Another reason for high discontinuation rates in Korea could be a lack of long-lasting educational programs supported by the government for T1D patients on diabetes technologies such as CGMs or insulin pump therapy. The Korean National Health Insurance System started reimbursing the cost of insulin pump devices for patients with T1D in January 2020. ${ }^{13)}$ As the adoption of insulin pump therapy is expected to increase, further structured education for T1D patients should be developed.

We found that older patients and those with longer diabetes duration were more likely to discontinue pump therapy, similar to the results in previous studies. ${ }^{17-19,23)}$ Individuals who started insulin pump therapy before the age of 10 years continued the pump therapy during the course; this indicates the impact of parental guidance on the diabetes care of young children, which contributes to higher rates of adherence. Meanwhile, a shorter duration at baseline may reflect the lack of experience with alternative treatments other than insulin pumps, which may lead to sustained pump use. Increasing trends have been observed in initiating insulin pump therapy earlier in the course of childhood $\mathrm{T} 1 \mathrm{D}{ }^{24,25)}$ with data showing its safety and efficacy for glycemic control. ${ }^{26,27)}$ Considering the benefits of insulin pump therapy, appropriate information and education about pump therapy use should be provided to patients with T1D and their family members in the early days of diabetes. However, at the time of initial T1D diagnosis, intensive education for T1D management is required, and the patients and their families need time to cope with the new diagnosis. In addition, education for insulin pump technology requires additional time to ensure relevant use. Our centers currently provide initial diabetes education about insulin injection, which is then changed to insulin pump therapy in those judged suitable for this treatment after assessment and discussion with the patients and their families.

The most common cause of discontinuation was physical problems, including skin reactions or interference with physical activity, which is similar to the results in previous studies. ${ }^{19,28)}$ No participants reported glycemic control issues as causes for discontinuation. In this study, we used the MiniMed 640G device, which is relatively large in size $(5.3 \times 9.6 \times 2.5 \mathrm{~cm})$, for initial insulin pump therapy. Insulin delivery devices are rapidly changing, and smaller, tubeless devices with increased wearability are being developed, ${ }^{29)}$ which may lead to wider adoption of insulin pump therapy in the future. Meanwhile, another common cause of discontinuation was the high cost of the pump device and supplies. The Korean National Health Insurance System has started to cover partial costs of insulin pump devices. ${ }^{13)}$ Thus, a higher number of patients will benefit from insulin pump therapy. Additionally, structured ongoing education with a follow-up system is of the utmost importance to improve adherence to insulin pump therapy. ${ }^{4)}$ Monitoring and encouragement through self-help groups among insulin pump users may be another beneficial option. Improving the social awareness of childhood T1D, including wearing the device in everyday life, is also needed.

After 1 year of insulin pump therapy, the HbAlc levels of the participants in the continuation group decreased significantly by $0.8 \%$. Based on previous meta-analyses ${ }^{30-32)}$ and registry 
data ${ }^{8}{ }^{8}$ insulin pump therapy was associated with a modest reduction in HbAlc levels $(0.2 \%-0.3 \%)$ without increased risk of hypoglycemia in pediatric patients with T1D. Recently, a large population-based observational study has shown that insulin pump therapy can facilitate better glycemic control than MDI. ${ }^{33)}$ Although we only evaluated a small number of patients for a short duration, our study revealed that insulin pump therapy has beneficial metabolic effects among children and young adults with T1D. Meanwhile, there was no significant increase in BMI $z$-scores or TDD in our patients. However, the use of more insulin with frequent meals among pump users has been associated with an increase in BMI $z$-scores. ${ }^{34)}$ Thus, ongoing education about proper diets is required during pump therapy.

Four patients presented with DKA during the pump therapy, which was associated with poor adherence to therapy. Although DKA had been considered more common among users of pumps based on older technologies, ${ }^{35)}$ recent observational studies and registry data have shown a similar or even decreased risk of DKA in pump users compared to that in MDI users. ${ }^{33,36)}$ Regardless of these data, DKA remains a major concern for insulin pump therapy, as any causes of insulin delivery failure can lead to DKA, ${ }^{15,37)}$ as seen in our patients. The prolonged use of catheters increases the risk of infusion set failures, such as blockage, kinking, loss of adhesion, or accidental pullout, and all of these can lead to the development of DKA. ${ }^{37,38)}$ Appropriate continuous education on the risk of DKA, the importance of infusion set changing, and the management of persistent hyperglycemia by carrying extra insulin pens to prepare for infusion set failure should be emphasized in insulin pump users.

This study had several limitations. It had a retrospective design, a small number of patients, and a short follow-up duration, which limited the statistical power to show significant changes in BMI $z$-scores or TDD after insulin pump therapy. Although this study showed significant improvement in glycemic control after insulin pump therapy, we could not compare the frequency and severity of hypoglycemia prior to therapy due to the absence of CGM data. This study did not include a control group treated with MDI or conventional insulin pump therapy without CGM for comparison of metabolic outcomes. In addition, individual adherence to pump therapy could not be evaluated, except during regular follow-ups at the outpatient clinic, owing to limited access to personal uploaded data. Due to the same reason, the evaluation of glycemic variability or the incidence of severe hypoglycemia could not be performed. Despite these limitations, this study was the first to show the durability and efficacy of insulin pump therapy among pediatric and young adult patients with T1D in Korea, and the results of the current study can be used as a basis for future studies about insulin pump therapy in patients with T1D in Korea.

In conclusion, insulin pump therapy was a durable and effective means of insulin treatment among patients with T1D in Korea. More than $80 \%$ of patients continually received insulin pump therapy, with significant improvements in $\mathrm{HbAlc}$ levels after 1 year of treatment. Patients in the discontinuation group were older and had a longer diabetes duration at pump initiation, indicating the need for an early introduction and ongoing education about insulin pump therapy. Further larger follow-up studies are needed to determine the long-term effects of insulin pump therapy use among patients with T1D in Korea.

\section{Ethical statement}

This study protocol was reviewed and approved by the Institutional Review Boards (IRBs) of Seoul National University Hospital (IRB number: H-2002-156-1105) and Seoul National University Bundang Hospital (IRB number: B-2004-604-401) with waiver of informed consent.

\section{Conflict of interest}

No potential conflict of interest relevant to this article was reported.

\section{Supplementary material}

Supplementary Fig. 1 can be found via https://doi.org/ apem.2040048.024.

\section{References}

1. DiMeglio LA, Evans-Molina C, Oram RA. Type 1 diabetes. Lancet 2018;391:2449-62.

2. American Diabetes A. 6. Glycemic targets: standards of medical care in diabetes-2020. Diabetes Care 2020;43:S6676.

3. Tauschmann M, Hovorka R. Technology in the management of type 1 diabetes mellitus - current status and future prospects. Nat Rev Endocrinol 2018;14:464-75.

4. Sherr JL, Tauschmann M, Battelino T, de Bock M, Forlenza G, Roman R, et al. ISPAD Clinical Practice Consensus Guidelines 2018: diabetes technologies. Pediatr Diabetes 2018;19 Suppl 27:302-25.

5. Bergenstal RM, Klonoff DC, Garg SK, Bode BW, Meredith M, Slover RH, et al. Threshold-based insulin-pump interruption for reduction of hypoglycemia. N Engl J Med 2013;369:224-32.

6. DiMeglio LA, Acerini CL, Codner E, Craig ME, Hofer SE, Pillay K, et al. ISPAD Clinical Practice Consensus Guidelines 2018: glycemic control targets and glucose monitoring for children, adolescents, and young adults with diabetes. Pediatr Diabetes 2018;19 Suppl 27:105-14.

7. American Diabetes A. 13. Children and adolescents: standards of medical care in diabetes-2020. Diabetes Care 2020;43:S163-82.

8. Sherr JL, Hermann JM, Campbell F, Foster NC, Hofer SE, Allgrove J, et al. Use of insulin pump therapy in children 
and adolescents with type 1 diabetes and its impact on metabolic control: comparison of results from three large, transatlantic paediatric registries. Diabetologia 2016;59:8791.

9. Willi SM, Miller KM, DiMeglio LA, Klingensmith GJ, Simmons JH, Tamborlane WV, et al. Racial-ethnic disparities in management and outcomes among children with type 1 diabetes. Pediatrics 2015;135:424-34.

10. Kim JH, Lee CG, Lee YA, Yang SW, Shin CH. Increasing incidence of type 1 diabetes among Korean children and adolescents: analysis of data from a nationwide registry in Korea. Pediatr Diabetes 2016;17:519-24.

11. Mayer-Davis EJ, Lawrence JM, Dabelea D, Divers J, Isom S, Dolan $\mathrm{L}$, et al. Incidence trends of type 1 and type 2 diabetes among youths, 2002-2012. N Engl J Med 2017;376:1419-29.

12. On Ministry of Food \& Drug Safety. Insulin infusion system approval No. 16-264 (in Korean) [Internet]. Cheongju (Korea): Ministry of Food \& Drug Safety; 2016 [cited 2020 Mar 9]. Available from: https://emed.mfds.go.kr.

13. On Ministry of Health and Welfare. Ministry of Health and Welfare Notification No. 2019-295 (in Korean) [Internet]. Sejong (Korea): Ministry of Health and Welfare; 2019 [cited 2020 Mar 9]. Available from: http://www.mohw.go.kr/react.

14. Kim JH, Yun S, Hwang SS, Shim JO, Chae HW, Lee YJ, et al. The 2017 Korean National Growth Charts for children and adolescents: development, improvement, and prospects. Korean J Pediatr 2018;61:135-49.

15. Wolfsdorf JI, Glaser N, Agus M, Fritsch M, Hanas R, Rewers A, et al. ISPAD Clinical Practice Consensus Guidelines 2018:diabetic ketoacidosis and the hyperglycemic hyperosmolar state. Pediatr Diabetes 2018;19 Suppl 27:15577.

16. Song SO, Jung CH, Song YD, Park CY, Kwon HS, Cha BS, et al. Background and data configuration process of a nationwide population-based study using the korean national health insurance system. Diabetes Metab J 2014;38:395-403.

17. Hofer SE, Heidtmann B, Raile K, Frohlich-Reiterer E, Lilienthal E, Berghaeuser MA, et al. Discontinuation of insulin pump treatment in children, adolescents, and young adults. A multicenter analysis based on the DPV database in Germany and Austria. Pediatr Diabetes 2010;11:116-21.

18. de Vries L, Grushka Y, Lebenthal Y, Shalitin S, Phillip M. Factors associated with increased risk of insulin pump discontinuation in pediatric patients with type 1 diabetes. Pediatr Diabetes 2011;12:506-12.

19. Wong JC, Boyle C, DiMeglio LA, Mastrandrea LD, Abel KL, Cengiz E, et al. Evaluation of pump discontinuation and associated factors in the T1D exchange clinic registry. J Diabetes Sci Technol 2017;11:224-32.

20. Wong JC, Dolan LM, Yang TT, Hood KK. Insulin pump use and glycemic control in adolescents with type 1 diabetes: Predictors of change in method of insulin delivery across two years. Pediatr Diabetes 2015;16:592-9.

21. Shulman R, Stukel TA, Miller FA, Newman A, Daneman
D, Guttmann A. Insulin pump use and discontinuation in children and teens: a population-based cohort study in Ontario, Canada. Pediatr Diabetes 2017;18:33-44.

22. Chamberlain JJ, Gilgen E. Do perceptions of insulin pump usability impact attitudes toward insulin pump therapy? A pilot study of individuals with type 1 and insulin-treated type 2 diabetes. J Diabetes Sci Technol 2015;9:105-10.

23. Wood JR, Moreland EC, Volkening LK, Svoren BM, Butler DA, Laffel LM. Durability of insulin pump use in pediatric patients with type 1 diabetes. Diabetes Care 2006;29:235560.

24. Lin MH, Connor CG, Ruedy KJ, Beck RW, Kollman C, Buckingham B, et al. Race, socioeconomic status, and treatment center are associated with insulin pump therapy in youth in the first year following diagnosis of type 1 diabetes. Diabetes Technol Ther 2013;15:929-34.

25. Berghaeuser MA, Kapellen T, Heidtmann B, Haberland $\mathrm{H}$, Klinkert C, Holl RW, et al. Continuous subcutaneous insulin infusion in toddlers starting at diagnosis of type 1 diabetes mellitus. A multicenter analysis of 104 patients from 63 centres in Germany and Austria. Pediatr Diabetes 2008;9:590-5.

26. Ramchandani N, Ten S, Anhalt H, Sinha S, Ching J, Finkelstein A, et al. Insulin pump therapy from the time of diagnosis of type 1 diabetes. Diabetes Technol Ther 2006;8:663-70.

27. Brancato D, Fleres M, Aiello V, Saura G, Scorsone A, Ferrara $\mathrm{L}$, et al. The effectiveness and durability of an early insulin pump therapy in children and adolescents with type 1 diabetes mellitus. Diabetes Technol Ther 2014;16:735-41.

28. Seereiner S, Neeser K, Weber C, Schreiber K, Habacher W, Rakovac I, et al. Attitudes towards insulin pump therapy among adolescents and young people. Diabetes Technol Ther 2010;12:89-94.

29. Zimmerman C, Albanese-O'Neill A, Haller MJ. Advances in type 1 diabetes technology over the last decade. Eur Endocrinol 2019;15:70-6.

30. Weissberg-Benchell J, Antisdel-Lomaglio J, Seshadri R. Insulin pump therapy: a meta-analysis. Diabetes Care 2003;26:1079-87.

31. Benkhadra K, Alahdab F, Tamhane SU, McCoy RG, Prokop LJ, Murad MH. Continuous subcutaneous insulin infusion versus multiple daily injections in individuals with type 1 diabetes: a systematic review and meta-analysis. Endocrine 2017;55:77-84.

32. Jeitler K, Horvath K, Berghold A, Gratzer TW, Neeser K, Pieber TR, et al. Continuous subcutaneous insulin infusion versus multiple daily insulin injections in patients with diabetes mellitus: systematic review and meta-analysis. Diabetologia 2008;51:941-51.

33. Karges B, Schwandt A, Heidtmann B, Kordonouri O, Binder E, Schierloh U, et al. Association of insulin pump therapy vs insulin injection therapy with severe hypoglycemia, ketoacidosis, and glycemic control among children, adolescents, and young adults with type 1 diabetes. JAMA 
2017;318:1358-66.

34. Birkebaek NH, Kahlert J, Bjarnason R, Drivvoll AK, Johansen A, Konradsdottir E, et al. Body mass index standard deviation score and obesity in children with type 1 diabetes in the Nordic countries. HbAlc and other predictors of increasing BMISDS. Pediatr Diabetes 2018;19:1198-205.

35. Hanas R, Lindgren F, Lindblad B. A 2-yr national population study of pediatric ketoacidosis in Sweden: predisposing conditions and insulin pump use. Pediatr Diabetes 2009;10:33-7.

36. Maahs DM, Hermann JM, Holman N, Foster NC, Kapellen TM, Allgrove J, et al. Rates of diabetic ketoacidosis: international comparison with 49,859 pediatric patients with type 1 diabetes from England, Wales, the U.S., Austria, and Germany. Diabetes Care 2015;38:1876-82.

37. Ross PL, Milburn J, Reith DM, Wiltshire E, Wheeler BJ. Clinical review: insulin pump-associated adverse events in adults and children. Acta Diabetol 2015;52:1017-24.

38. Pfutzner A, Sachsenheimer D, Grenningloh M, Heschel M, Walther-Johannesen L, Gharabli R, et al. Using insulin infusion sets in csii for longer than the recommended usage time leads to a high risk for adverse events: results from a prospective randomized crossover study. J Diabetes Sci Technol 2015;9:1292-8. 